\title{
УДК 613.6+613.64/534-6:001.5
}

\section{ОБОСНОВАНИЕ БЕВОПАСНОЙ СТАЖКЕВОЙ ЭКСПОЗИШИИ ИНФРАЗВУКА У ГОРНОРАБОЧИХ УГОльНЫХ ШАХТ}

\author{
Соловьев А.И., Назаренко В.И.
}

\section{ГП НИИ меАИко-экологических проблем $\triangle$ онбасса и угольной промышленности, Г. $\Delta$ онешк Институт меАишины труда АМН Украины, г. Киев}

Проведены комплексные исследования параметров инфразвука, шума, общей и локальной вибрации на угольных шахтах Донбасса. Установлено, что наиболее неблагоприятные условия труда по виброакустическим факторам формируются при ведении очистных работ. При этом эквивалентные уровни звука и общие уровни звукового давления на рабочих местах соответствуют критериям 1-3 степени 3 класса Гигиенической классификации труда ГН 3.35-3.3.8; 6.6.1-083-2001, а эквивалентные корректированные уровни локальной вибрации отвечают, в основном, 3-4 степени 3 класса (вредный). Основными источниками фонового инфразвука с уровнями 98-102 дБ Лин являются системы шахтного проветривания, подземный шахтный транспорт и углевыемочное оборудование. Установлено, что пороговая стажевая экспозиционная доза инфразвука до появления жалоб, связанных с его профессиональным воздействием на горнорабочих, равняется 112 дБ Лин

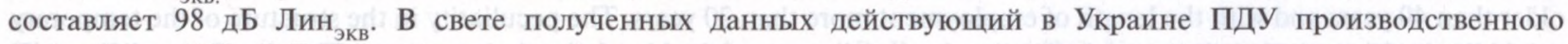
инфразвука (110 дБ Лин) требует дальнейшего уточнения.

Ключевые слова: условия труда горнорабочих, виброакустические факторы, инфразвук, шум, вибрация, стажевая экспозиционная доза

\section{Введение}

В современной угледобывающей промышленности, в связи с широким внедрением интенсивных технологий разработок угольных пластов, большое значение приобретает санитарно-гигиенический мониторинг виброакустических факторов, преимущественно низкочастотного диапазона [1]. При этом отмечается, что на большинстве рабочих мест горняков возникает комбинированное воздействие инфразвука, низкочастотного шума и вибрации, при котором акустические колебания охватывают диапазон от 2 до 125 Гц, а вибрация - от 1 до 20 Гц. В данном комплексе инфразвуковой компонент и его влияние на человека в производственных условиях являются наименее изученными. Согласно существующему мнению, оценка экспозиции (exposure assessment) неблагоприятного фактора является «...этапом оценки риска, заключающейся в качественном и количественном анализе присутствия любого агента (включая его производные), который может присутствовать в данной среде, и суждение о возможных последствиях для данной популяции в конкретном случае» [2]. Н.Ф.Измеров и др.(1998) отмечают, что при воздействии интенсивных низ- кочастотных акустических колебаний возникают самые разнообразные неспецифические реакции, в первую очередь, со стороны центральной нервной системы: в виде нарушений в психоэмоциональной сфере, диэнцефальных кризов, возможного развития специфического «инфразвукового» (гипоталамического) синдрома [3]; часто возникают нарушения со стороны сердечно-сосудистой системы [4], а при комбинированном действии с низкочастотной вибрацией повышена вероятность одновременного появления нескольких форм профессиональных и сопутствующих им профессионально обусловленных заболеваний с включением в процесс нервно-мышечного, опорно-двигательного аппарата и вестибулярного анализатора [5].

Н.Ф.Измеров, Н.А.Куралесин, (1997) описали симптомокомплекс нарушений, вызванных влиянием инфразвука, и разработали критерии его неблагоприятного действия для разных экспозиций и уровней риска для здоровья работающих [3]. Очень важным, по нашему мнению, является сопоставление риска нарушений здоровья с биологическими эффектами, вызванными инфразвуком, особенно, при комбинированном воздействии с другими производственными факторами. 
В качестве адекватной методики оценки профессионального риска при воздействии шума D.W.Robinson (1968) предложил определение «стажевой экспозиционной дозы» [11], расчет которой в дальнейшем был усовершенствован Э.И.Денисовым (2001) [2]. Рядом исследований, проведенных на угольных шахтах, установлены величины пограничной стажевой экспозиционной дозы шума 105-108 дБА, вибрации - 100-103 дБ (Д.О.Ластков, 2001) ['6]. По данным В.В.Мухина (1994), стажевая экспозиционная доза шума в 106 дБА соответствовала зоне перехода от стадии утомления слухового анализатора к стойкому снижению слуха [7]. В других отраслях оценку риска профессиональной тугоухости на примере механизаторов сельского хозяйства выполнили Ю.И.Кундиев и др. (1999) [8]. Показано, что в данной профессии стажевая доза шума равнялась 108,5 дБА. Минимальный расчетный риск заболевания профессиональной тугоухостью ( $1 \%$ заболевших) соответствовал стажевой дозе шума 99 дБ экв.

Целью данного исследования является изучение условий труда горнорабочих угольных шахт по комплексу виброакустических факторов и гигиеническая оценка этих факторов в соответствии с критериями ГН 3.35-3.3.8; 6.6.1-083-2001 [9], а также определение биологической значимости инфразвука в шахтах и расчет его пороговой экспозиционной дозы, при которой начинает проявляться его специфическое действие на организм, согласно данным литературы.

\section{Материалы и методы исследований}

Санитарно-гигиенические исследования комплекса виброакустических факторов проведены в соответствии с требованиями ДСН 3.3.6.037-99 и ДСН 3.3.6.039-99. Измерение и оценка инфразвука на рабочих местах шахтного комплекса произведена по общему уровню звукового давления в дБ Лин. Так как практически на всех рабочих местах инфразвук, и шум были непостоянными, то основным параметром для оценки виброакустических факторов были эквивалентные уровни, учитывающие время действия факторов в течение смены.

Экспозиционная стажевая доза и безопасный стаж работы, основанные на правиле «равной энергии» с принятым параметром эквивалентности $q=3$, определена по формуле, предложенной
Э.И.Денисовым [2], и представляет собой сумму сменных доз (имеется в виду эквивалентных по энергии уровней) за трудовой стаж:

$$
\mathrm{L}_{\mathrm{DUT}}=\mathrm{L}_{\mathrm{Ui} \uparrow \kappa \mathrm{B}}+10 \mathrm{Lg} \frac{\mathrm{T}}{\mathrm{T}_{0}},
$$

где $\mathrm{L}_{\mathrm{DUT}}-$ уровень суммарной экспозиционной стажевой дозы кинематических параметров, выраженный в относительных логарифмических величинах (дБ, дБА, дБ Лин); $\mathrm{L}_{\mathrm{Ui}}$ экв - эквивалентный за смену уровень изучаемого параметра, Т - стаж работы (в годах), $\mathrm{T}_{0}-1$ год. Если на протяжении трудового стажа был контакт с различными типами машин и оборудования, то проводилось энергетическое суммирование уровней в соответствии с ДСН 3.3.6.037-99.

Анкетный опрос 184 рабочих подземного и поверхностного шахтного комплекса и углеобогащения, потенциально подверженных воздействию инфразвука, вибрации и шума, проведен с целью выделения фактор-зависимых жалоб и сопоставления их с полученными дозами факторов. Перечень жалоб в анкете составлен из симптомов, которые наиболее часто встречались при воздействии инфразвука и/или низкочастотного шума и вибрации по литературным данным [10].

\section{Результаты исследований и их обсуждение}

Обобщенные результаты расчета интегральных показателей шума $\left(\mathrm{L}_{\mathrm{A} \mathrm{экв.}}\right)$, инфразвука $\left(\mathrm{L}_{\text {Лин экв. }}\right)$, вибрации $\left(\mathrm{L}_{\text {экв. корр. }}\right)$ на основании проведенных гигиенических исследований виброакустических факторов на рабочих местах 6 глубоких угольных шахт Донбасса представлены в табл. 1.

Сопоставление результатов измерений уровней шума, вибрации и инфразвука с гигиеническими критериями условий труда [9] показало, что наиболее неблагоприятные условия по виброакустическим факторам характерны для рабочих мест при ведении очистных работ. Эквивалентные уровни звука и звукового давления соответствовали вредным условиям труда класса $3.1-3.3$, а эквивалентные корректированные уровни вибрации - классам 3.4 и 4 .

При использовании в качестве усредненных для данного вида работ параметров шумовой и вибрационной нагрузки средних арифметических значений видна заниженная оценка условий труда при сравнении с аналогичными показателями, рассчитанными методом энергетического суммирования. При этом, оценка степени превышения допустимых 
Таблица 1

Характеристика условий труда по виброакустическим факторам на угольных шахтах Донбасса

\begin{tabular}{|c|c|c|c|c|c|c|}
\hline \multirow{3}{*}{$\begin{array}{c}\text { Виды } \\
\text { выполняемых } \\
\text { работ }\end{array}$} & \multirow{3}{*}{ 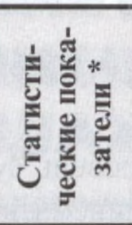 } & \multirow{3}{*}{$\begin{array}{c}\begin{array}{c}\text { Экв. уро- } \\
\text { вень звука, } \\
\text { LА экв., }\end{array} \\
\text { дБА экв. } \\
\end{array}$} & \multirow{3}{*}{$\begin{array}{c}\begin{array}{c}\text { Экв. уровень } \\
\text { звукового } \\
\text { давления Lлин, }\end{array} \\
\text { дБ Линэкв. } \\
\end{array}$} & \multicolumn{2}{|c|}{$\begin{array}{l}\text { Вибрация (эквивалент- } \\
\text { ный корректированный } \\
\text { уровень виброускорения) }\end{array}$} & \multirow{3}{*}{$\begin{array}{c}\text { Условия труда по } \\
\text { шуму। } \\
\text { инфразвуку/ } \\
\text { вибрации по ГКТ } \\
\text { ГН 3.35-3.3.8; } \\
6.6 .1-083-2001 \\
\end{array}$} \\
\hline & & & & локальная & общая & \\
\hline & & & & 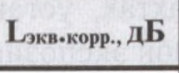 & Lокв-корр., дБ & \\
\hline \multirow{3}{*}{$\begin{array}{l}\text { Очистные работы на } \\
\text { шахтах с пологим зале- } \\
\text { ганием угольных пластов }\end{array}$} & $\overline{\mathrm{x}} \pm \mathrm{m}_{\overline{\mathrm{x}}}$ & $90,4 \pm 3,2$ & $103,9 \pm 7,6$ & $90,4 \pm 2,2$ & - & $3.2 / 2 / 4$ \\
\hline & $\overline{\mathbf{X}}_{\text {энерг }}$ & 92,3 & 114,5 & 91,3 & - & $3.2 / 3.1 / 4$ \\
\hline & $\delta$ & 4,6 & 11,0 & 3,1 & - & \\
\hline \multirow{3}{*}{$\begin{array}{l}\text { Tо же с крутым залега- } \\
\text { нием угольных пластов }\end{array}$} & $\overline{\mathrm{x}} \pm \mathrm{m}_{\overline{\mathrm{x}}}$ & $95,3 \pm 10,8$ & $103,0 \pm 16,7$ & $88,0 \pm 1,1$ & - & $3.3 / 2 / 3.4$ \\
\hline & $\overline{\mathbf{X}}_{\text {энерг }}$ & 100,7 & 115,0 & 88,0 & - & $3.3 / 3.1 / 3.4$ \\
\hline & $\delta$ & 9,5 & 14,8 & 1,0 & - & \\
\hline \multirow{3}{*}{$\begin{array}{l}\text { Общие профессии } \\
\text { на очистных работах }\end{array}$} & $\overline{\mathrm{x}} \pm \mathrm{m}_{\overline{\mathrm{x}}}$ & $86,7 \pm 3,5$ & $101,2 \pm 4,0$ & $90,8 \pm 1,6$ & - & $3.2 / 2 / 4$ \\
\hline & $\overline{\mathrm{X}}_{\text {энерг }}$ & 93,8 & 112,6 & 92,1 & - & $3.2 / 3.1 / 4$ \\
\hline & $\delta$ & 9,0 & 10,3 & 4,0 & - & \\
\hline \multirow{3}{*}{$\begin{array}{l}\text { Подготовительные рабо- } \\
\text { ты при буровзрывном } \\
\text { способе проходки }\end{array}$} & $\overline{\mathrm{x}} \pm \mathrm{m}_{\overline{\mathrm{x}}}$ & $93,4 \pm 6,4$ & $96,7 \pm 5,6$ & $91,0 \pm 1,1$ & $75,5 \pm 11,4$ & $3.2 / 2 / 4$ \\
\hline & $\overline{\mathbf{X}}_{\text {энерг }}$ & 101,8 & 103,7 & 91,1 & 81,1 & $3.3 / 2 / 4$ \\
\hline & $\delta$ & 9,7 & 8,6 & 1,0 & 10,1 & \\
\hline \multirow{3}{*}{$\begin{array}{l}\text { Tо же при } \\
\text { буропогрузочном } \\
\text { способе проходки }\end{array}$} & $\overline{\mathrm{x}} \pm \mathrm{m}_{\overline{\mathrm{x}}}$ & $86,7 \pm 5,3$ & $94,5 \pm 5,1$ & $91,5 \pm 2,9$ & $76,5 \pm 3,8$ & $3.2 / 2 / 4$ \\
\hline & $\overline{\mathbf{X}}_{\text {энерг }}$ & 90,7 & 99,9 & 92,8 & 79,3 & $3.2 / 2 / 4$ \\
\hline & $\delta$ & 8,9 & 8,6 & 4,9 & 6,4 & \\
\hline \multirow{3}{*}{$\begin{array}{l}\text { Общие профессии на } \\
\text { подготовительных } \\
\text { работах }\end{array}$} & $\overline{\mathrm{x}} \pm \mathrm{m}_{\overline{\mathrm{x}}}$ & $83,2 \pm 4,5$ & $92,0 \pm 3,8$ & - & - & $3.1 / 2 /-$ \\
\hline & $\overline{\mathbf{x}}_{\text {энерг }}$ & 89,6 & 99,5 & - & - & $3.2 / 2 /-$ \\
\hline & $\delta$ & 9,8 & 8,3 & + & - & \\
\hline \multirow{3}{*}{$\begin{array}{l}\text { Участок шахтного } \\
\text { транспорта }\end{array}$} & $\overline{\mathrm{x}} \pm \mathrm{m}_{\overline{\mathrm{x}}}$ & $81,3 \pm 2,9$ & $95,3 \pm 2,4$ & - & $64,2 \pm 8,6$ & $3.1 / 2 / 4$ \\
\hline & $\overline{\mathbf{X}}_{\text {энерг }}$ & 85,1 & 99,9 & - & 71,1 & $3.2 / 2 / 4$ \\
\hline & $\delta$ & 7,9 & 6,5 & - & 9,9 & \\
\hline \multirow{3}{*}{$\begin{array}{l}\text { Технологический } \\
\text { комплекс на поверхности }\end{array}$} & $\overline{\mathrm{x}} \pm \mathrm{m}_{\overline{\mathrm{x}}}$ & $84,2 \pm 6,6$ & $94,4 \pm 5,6$ & - & $55,1 \pm 9,5$ & $3.1 / 2 / 3.1$ \\
\hline & $\overline{\mathbf{X}}_{\text {энерг }}$ & 94,5 & 102,1 & - & 67,5 & $3.2 / 2 / 4$ \\
\hline & $\delta$ & 12,6 & 9,9 & - & 14,5 & \\
\hline \multirow{3}{*}{$\begin{array}{l}\text { Прочие профессии на } \\
\text { поверхностном } \\
\text { комплексе }\end{array}$} & $\overline{\mathrm{x}} \pm \mathrm{m}_{\overline{\mathrm{x}}}$ & $82,1 \pm 7,0$ & $86,2 \pm 4,5$ & - & $40,3 \pm 1,9$ & $3.1 / 2 / 2$ \\
\hline & $\overline{\mathrm{X}}_{\text {энерг }}$ & 90,4 & 90,4 & - & 41,2 & $3.2 / 2 / 2$ \\
\hline & $\delta$ & 11,9 & 7,6 & - & 3,2 & \\
\hline
\end{tabular}

$\bar{x} \pm m_{\bar{x}}-$ среднее арифметическое и доверительный интервал при уровне значимости $P<0,05$;

$\bar{x}_{\text {энерг }}$ - среднее при энергетическом суммировании;

$\delta$ - стандартное отклонение.

уровней звукового давления на очистных работах вторым, более адекватным методом позволяет отнести условия труда к вредным 3 -го класса 1 -й степени, в то же время по оценке условий труда обычным арифметическим усреднением они характеризуется как 2-го класса (допустимый). Представленные в табл. 1 показатели могут быть использованы при подготовке типовых санитарно-гигиенических характеристик рабочих мест по виброакустическим факторам на угольных шахтах.

Группировка обследованных рабочих мест по гигиеническим критериям классификации условий труда [9], по фактору «шум» и сопутствующие ему в этих группах уровни инфразвука $\left(\mathrm{L}_{\text {Лин экв. }}\right)$ представлены в табл. 2.
В группу с допустимыми условиями труда по фактору шума вошли горнорабочие следующих профессий: горнорабочий подземный, машинист лебедки, электрослесарь, обслуживающий подземные машины, слесарь-ремонтник на участке по ремонту забойного оборудования. Средний уровень звука для группы с допустимыми условиями труда составил 76,6 дБА экв. а доверительный интервал при уровне значимости $\mathrm{P}<0,05$ находился в пределах 75,9-77,3 дБА, общий уровень звукового дав-

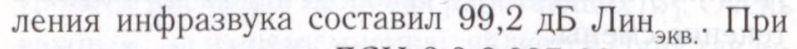
этом, по критериям ДСН 3.3.6.037-99, выраженный инфразвук присутствовал на рабочих местах, где уровень шума не превышал допустимый $(80$ дБА 
Средние интегральные показатели уровней звука $\left(\mathrm{L}_{\mathrm{A} \text { экв. }}\right)$ в зависимости от класса условий труда по данному фактору и сопутствующие им уровни инфразвука $\left(\mathrm{L}_{\text {Лин экв}}\right)$ на рабочих местах в угольных шахтах

\begin{tabular}{|c|c|c|c|c|c|}
\hline \multirow{3}{*}{$\begin{array}{l}\text { Нормируемые } \\
\text { параметры }\end{array}$} & \multicolumn{5}{|c|}{ Условия труда по ГКТ ГН 3.35-3.3.8; 6.6.1-083-2001 } \\
\hline & \multirow{2}{*}{$\begin{array}{c}\text { 2-й класс } \\
\text { (допустимые) }\end{array}$} & \multicolumn{4}{|c|}{ 3-й класс (вредные) } \\
\hline & & 3.1 & 3.2 & 3.3 & 3.4 \\
\hline Эквивалентный уровень шума, дБА экв. & $76,6 \pm 0,7$ & $83,8 \pm 0,7$ & $91,0 \pm 0,9$ & $101,8 \pm 2,1$ & $106,5 \pm 1,0$ \\
\hline $\begin{array}{l}\text { Эквивалентный общий уровень звуко- } \\
\text { вого давления инфразвука, дБ Лин экв. }\end{array}$ & $99,2 \pm 12,7$ & $98,3 \pm 3,0$ & $102,1 \pm 2,8$ & $117,0 \pm 9,0$ & $107,5 \pm 1,0$ \\
\hline 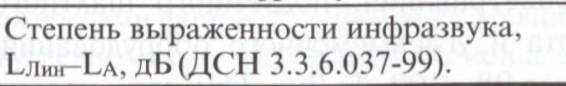 & $\begin{array}{c}23 \\
\text { (выражен) }\end{array}$ & $\begin{array}{c}15 \\
\text { (не выражен) }\end{array}$ & $\begin{array}{c}11 \\
\text { (не выражен) }\end{array}$ & $\begin{array}{c}15 \\
\text { (не выражен) }\end{array}$ & $\begin{array}{c}1 \\
\text { (отсутствует) }\end{array}$ \\
\hline
\end{tabular}

Условия труда 1 -й степени 3 -го класса по фактору «шум» характерны для горнорабочих очистного забоя (ГРОЗ) и машинистов горных выемочных машин (МГВМ), занятых на очистных работах с применением комбайнов серийных марок типа $1 \mathrm{~K} 101$, проходчиков, занятых на погрузке горной массы погрузчиками, непрерывного типа ППН-5, а также горнорабочих участка шахтного транспорта: машинистов конвейеров базовых моделей ЗЛ100У, $2 Л 120,1 Л 100$ и группы прочих вспомогательных профессий (слесарь-ремонтник, опрокидчик, машинист лебедки). Для этих профессий характерен средний уровень звука 83,8 дБА экв. с доверительным интервалом (95\%) 83,1-84,5 дБА, а соответствующий этим рабочим местам средний уровень инфразвука составил близкий для группы с допустимыми условиями труда, но с меньшим варьирова-

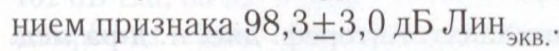

Наиболее многочисленной оказалась группа горнорабочих с превышением ПДУ 3 класса 2 -й степени. Средние уровни звука здесь составили $91,0 \pm 0,9$ дБА $_{\text {экв}}$, а уровень сопутствующего инфразвука - $102,1 \pm 2,8$ дБ Лин вошли, из основных профессий, на очистных работах - забойщики на отбойных молотках MO2, MO2M, МО2Б и других аналогичных моделях; машинисты, обслуживающие угольные комбайны типа 2ҚЦТГ; на подготовительных работах - проходчики при буровзрывном способе проходки, занятые погрузкой породы породопогрузочными машинами ковшевого типа и бурением шпуров серийной горной техникой; горнорабочие очистного забоя (ГРОЗ), занятые бурением шпуров горными сверлами СЭР19, СР31М. На участке шахтного транспорта эта группа представлена следующими профессиями: машинисты электровоза АМ8Д и ГРОЗ, сопровождающие состав с людьми, машинисты, обслуживающие скребковые конвейера типа СП63.
На поверхностном комплексе данные условия труда характерны для горнорабочих, обслуживающих вентиляционные установки ВЦД 31,5 , ВОД 30 ; машинистов насосных установок ВВН-150, грохотовщиков, обслуживающих грохота ГИЛ-1 и аналоги.

В группу с вредными условиями труда 3-го класса 3 степени со средним уровнем звука $101,8 \pm 2,1$ дБА и соответствующим ему уровнем инфразвука -

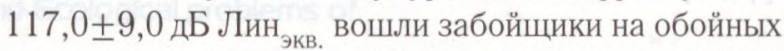
молотках типа МО6П, МО6ПМ и аналоги; МГВМ, обслуживающие угольные комбайны ГШ-68 и Поиск-2; ГРОЗ на пологих пластах, занятые бурением шпуров перфораторами ПП54В; машинисты шахтных холодильных установок типа 21 ШМКТ-80; машинисты поршневых и центробежных компрессорных установок 55В100/8, ТK-250.

Наиболее неблагоприятные условия труда 3-го класса 4 -й степени по шумовому фактору установлены на рабочих местах бригады проходчиков при буровзрывном способе проходки, которые постоянно заняты бурением шпуров перфораторами ПП54В и машинистов турбокомпрессорных установок типа ТK-500. Средний уровень звука и пределы доверительного интервала здесь составили $106,5 \pm 1,0$ дБА фразвука $-107,5 \pm 1,0$ дБ Лин экв. .

Обращают внимание недостоверные отличия уровней инфразвука в группах $2-3,2$ классов условий труда по шуму. Этот факт можно интерпретировать как фоновый уровень постоянно присутствующего в шахте инфразвука, который равен в среднем 98-102 дБЛин.

Следующим этапом исследований явилось сопоставление частоты специфических жалоб по дан ным анкетного опроса со стажевой экспозиционной дозой шума и аналогичной дозой инфразвука. Установлено, что при достижении дозы шума в пределах 101-105 дБА экв. горнорабочие предъявляют 
достоверно чаще $(\mathrm{P}<0,05)$ жалобы, характерные для инфразвуковой симптоматики, что соответствует стажевой экспозионной дозе инфразвука $112-116$ дБ Лин ${ }_{э к в}$.

Используя эти данные, с помощью формулы (1) можно определить допустимый уровень инфразвука для полной рабочей смены при стаже работы 40 лет. Расчетная величина допустимого общего уровня инфразвука ( LЛин $\left._{\text {экв. }}\right)$ при этом составила

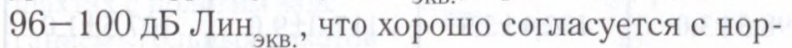
мативными уровнями принятыми в России (в зависимости от степени тяжести и напряженности трудового процесса - 95 или 100 дБ Лин) [10]. В УКраине норматив для производственного инфразвука составляет 110 дБЛин, что не обеспечивает реальную биологическую безопасность по данному фактору, особенно, в угольной отрасли, где существует тенденция к увеличению гигиенической значимости акустических колебаний и вибрации, со смещением максимальных уровней энергии в инфразвуковой и низкочастотный диапазон.

\section{Выводы}

1. Наиболее неблагоприятные условия труда на угольных шахтах по виброакустическим факторам характерны для рабочих мест при ведении очистных работ. Эквивалентные уровни звука и звукового давления, при этом, соот-

\section{Литература}

1. Соловьев А.И. Гигиеническая значимость виброакустического фактора инфранизкочастотного диапазона на угольных шахтах Донбасса // Сб. Гигиена труда.- Вып.35.- К., 2004.- С. 51-61.

2. Профессиональный риск. Справочник/Под ред. Н.Ф.Измерова, Э.И.Денисова.- М.: Социздат, 2001.-267 c.

3. Куралесин Н.А. Гигиенические и медико-биологические аспекты воздействия инфразвука // Медицина труда и пром. экол.- 1997.- №5.- С. 8-14.

4. Нехорошев А.С. Изучение механизма действия низкочастотных акустических колебаний // Медицина труда и пром. экол.- 1998.- №5.- С. 26-30.

5. Балунов В.Я., Барсуков А.Ф., Артамонова В.Г. Клинико-фунциональная оценка состояния здоровья работающих в условиях воздействия инфразвука, шума и общей вибрации // Медицина труда и пром. экол.- 1998.- №5.- С. 22-26.

6. Ластков Д.О. Гігієнічні основи профілактики шкідливої дії фізичних виробничних чинників на ветствуют вредным условиям труда $3.1-3.3$ класса, а эквивалентные корректированные уровни локальной вибрации - 3.4 и 4 классу. Вибрационный фактор является ведущим как на очистных, так и на подготовительных работах, поэтому, при выполнении данных работ, первостепенное внимание следует уделять вопросам виброзащиты.

2. Фоновые уровни инфразвука в шахтах, в первую очередь, связанные с работой систем шахтного проветривания, подземного шахтного транспорта и углевыемочного оборудования, составляют 98-102 дБ Лин. При этом уровни инфразвука, воздействующие на горнорабочих, практически не зависят от источников акустических колебаний на рабочих местах, уровни звука которых не превышают 96 дБА.

3. Пороговая стажевая экспозиционная доза инфразвука до появления первых симптомов его неблагоприятного профессионального воздействия составляет 112 дБ Лин ${ }_{э к в}$. Рекомендуемая величина среднесменного допустимого общего уровня инфразвука для горнорабочих -

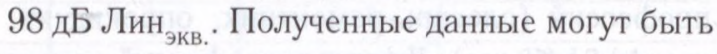
использованы при пересмотре отечественных санитарных нормативов по инфразвуку, как не обеспечивающих должной защиты здоровья работающих в условиях воздействия данного фактора.

гірників вугільних шахт: Автореф. дис. ... д-ра мед. наук.- Донецьк, 2001.- 35 с.

7. Мухин В.В. Устойчивость к акустической среде у рабочих современного производства и профилактика ее нарушений: Дисс. ... д-ра мед. наук.- Донецк, 1994.- $328 \mathrm{c}$.

8. Кундиев Ю.И., Чернюк В.И., Витте П.Н. Изучение профессионального риска на Украине // Медицина труда и пром. экол.- 1999.- №4.- С. 6-8.

9. Гігієнічна класифікація праці за показниками шкідливості та небезпечності факторів виробничого середовища, важкості і напруженості трудового процесу (ГН 3.35-3.3.8; 6.61-083-2001).- К.: затв. МОЗ України 27.12.2001 №528.- 26 с.

10. Инфразвук как фактор риска здоровью человека/Н.Ф.Измеров, Г.А.Суворов, Н.А.Куралесин, В.Г.Овакимов.- Воронеж, 1998.- 276 с.

11. Robinson D.W. The Relationship between Hearing Loss and Noise Exposure/NPL Aero Report.Teddington: National Physical Laboratory.-32 p. 


\section{Соловйов А.І., Назаренко В.I.

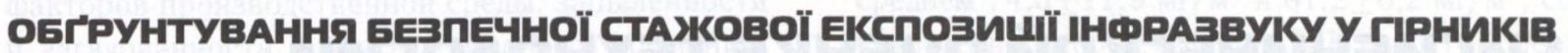 BУחИЬHИX ШАXт}

\section{$\Delta П \mathrm{H} \Delta \mathrm{l}$ меАико-екологічних проблем $\triangle$ онбасу і вугільної промисловості, м. $\triangle$ онешьк Інститут меАишини праші АМН України м. Київ}

Виконано комплексні дослідження параметрів інфразвуку, шуму, загальної і локальної вібрації на вугільних шахтах Донбасу. Встановлено, що найбільш несприятливі умови праці за віброакустичними чинниками відмічаються при веденні очисних робіт. При цьому еквівалентні рівні звуку і рівні звукового тиску на робочих місцях гірників відповідають критеріям 1-3 ступеня 3 класу Гігієнічної класифікації праці ГН 3.35-3.3.8; 6.6.1-083-2001, а еквівалентні кориговані рівні локальної вібрації відповідають, в основному, 3-4 ступеню 3 класу (шкідливий). Основними джерелами фонового інфразвуку з рівнями 98-102 дБ Лин є системи шахтного провітрювання, шахтний транспорт, вуглевиймальне обладнання. Встановлено, що порогова стажова експозиційна доза інфразвуку до появи перших скарг, пов'язаних з його специфічною дією на гірників, дорівнює 112 дБ Лин ${ }_{\text {екв. }}$, а розрахункова величина допустимого загального рівня звукового тиску на робочих місцях становить 98 дБ Лин екв. У світлі одержаних даних, діючий ГДР виробничого інфразвуку (110 дБ Лин) в Україні потребує подальшого уточнення.

Ключові слова: умови праці гірників, віброакустичні фактори, інфразвук, шум, вібрація, стажова експозиційна доза

\section{Soloviev A.I., Nazarenko V.I.}

\section{SUBSTANTIATION OF ULTRASOUND SAFE EXPOSURE LEVELS FOR COAL MINERS}

State Enterprise «Scientific Research Institute of Medical and Ecological problems of

Donbass and Coal Industry", Donetsk

Institute for Occupational Health of AMS of Ukraine, Kiev

Complex examinations of infrasound, noise, whole-body and hand-arm vibrations affecting miners of Donbass were carried out. It is stated that the most unfavourable working conditions by vibration-acoustic factors are formed at clearing works. In this equivalent levels of sound and levels of sound pressure on workplaces correspond to $1-3$ degrees of the 3 rd class in the Hygienic Classification of Labour ГН 3.3.5-3.3.8; 6.6.1-083-2001 and the equivalent corrected levels of hand arm vibration meet, mainly, to the $3-4$ degrees of the 3 rd class (harmful conditions). Systems of mine ventilation, underground mine transport, selected mining equipments is the main source of the background infrasound in coal mines with its levels of 98 $102 \mathrm{~dB}$ Lin, on the average. It was revealed that the threshold of exposure dose of infrasound before development of specific complaints related to occupational effect on coal miners comprised $112 \mathrm{~dB} \mathrm{Lin}$ eq. The calculated value of the permissible general level of infrasound pressure at workplaces was recommended as $98 \mathrm{~dB}$ Lin. In the light of the obtained data the existing permissible level of industrial infrasound $(110 \mathrm{~dB} \mathrm{Lin})$ in Ukraine requires further improvement.

Key words: working conditions of coal miners, vibration-acoustic factors, infrasound, noise, vibration, safe exposure levels

Поступила: 04.12.2005 2.

Контактное лицо: Назаренко В.И., Институт медицины труда АМН Украины, ул. Саксаганского, 75, Киев 01033, Украина 